\title{
A randomized clinical trial comparing safety, clinical and parasitological response to artemether-lumefantrine and chlorproguanil-dapsone in treatment of uncomplicated malaria in pregnancy in Mulago hospital, Uganda
}

\author{
Daniel Kabonge Kaye, ${ }^{1}$ Ruth Nshemerirwe, ${ }^{1}$ Twaha Serunjogi Mutyaba, ${ }^{1}$ Grace Ndeezi. ${ }^{2}$ \\ ${ }^{1}$ Department of Obstetrics and Gynecology, Makerere University Medical School, P.O. Box 7072, Kampala, Uganda. \\ ${ }^{2}$ Makerere University-University of California San-Francisco Research Collaboration, P.O. Box 7072, Kampala Uganda and \\ Department of Pediatrics and Child Health, Makerere University Medical School, P.O. Box 7072, Kampala, Uganda.
}

\begin{abstract}
Background: Malaria infection during pregnancy is a major public health problem. Due to increasing resistance to Chloroquine and Sulphadoxine/Pyrimethamine, the Ugandan national policy on malaria treatment was changed in 2005 to Artemisinin-based combination therapy (ACT) as the first-line treatment for uncomplicated malaria. The policy recommends assessment of safety and efficacy of alternative drugs for treatment of uncomplicated malaria. We compared the efficacy and safety of ArtemetherLumefantrine (Coartem $\AA$ ) and Chlorproguanil-Dapsone (Lapdap $\AA$ ) in the management of uncomplicated malaria in pregnancy. Methodology: We enrolled 110 pregnant women in the second and third trimester of pregnancy who presented to Mulago hospital, Uganda, with uncomplicated malaria. The study design was an open-label randomized clinical trial. Participants were randomized to receive either Artemether-Lumefantrine (Coartem ${ }^{\circledR} 20 \mathrm{mg} / 120 \mathrm{mg}$ ) orally or Chlorproguanil-Dapsone (Lapdap®) orally for 3 consecutive days. Primary endpoints were clinical and parasitological response assessed on days 0 , 1, 2, 4, 7, 14 and 28. Adverse effects, clinical response (treatment failure) and parasitological response were compared. Analysis was by intention to treat.

Results: Of the 100 women who completed the study, there was no statistically significant difference in clinical and parasitological response by Day 4. The mean fever clearance time 3.0 days with Lapdap® versus 2.5 days with Coartem ${ }^{\circledR}$ was comparable. Likewise, mean parasite clearance time of 2.4 and 2.2 days for Lapdap $\AA$ and Coartem $\AA$ respectively was comparable. The adverse effects were comparable between the two groups.

Conclusion: Artemether-Lumefantrine and Chlorproguanil-Dapsone have high and comparable cure rates and similar safety profiles when used for treatment of uncomplicated malaria in pregnancy.

Key Words: Artemether-Lumefantrine, Chlorproguanil-Dapsone, Malaria, uncomplicated malaria, pregnancy, Africa.
\end{abstract}

J Infect Developing Countries 2008; 2(2):135-139.

Received 24 July 2007 - Accepted 16 February 2008.

Copyright (c) 2007 Kaye et al. This is an open access article distributed under the Creative Commons Attribution License, which permits unrestricted use, distribution, and reproduction in any medium, provided the original work is properly cited.

\section{Introduction}

Malaria infection during pregnancy is a major public health problem in sub-Saharan Africa. Due to increasing resistance to Chloroquine and Sulphadoxine-Pyrimethamine [1], the Ugandan national policy on malaria treatment was changed in 2005 to Artemisinin-based combination therapy (ACT). Artemether-Lumefantrine (Coartem $\AA)$, a fixed combination drug containing Artemether (20mg) and Lumefantrine (120mg) per tablet for oral use (given as 4 tablets twice daily for 3 days) is the first-line treatment for uncomplicated malaria. The efficacy of Coartem ${ }^{\circledR}$ is well documented from studies conducted in different settings among children and adults [2,3]. Though
ACTs appear to be well tolerated and safe in pregnancy [4-7], there is a need to evaluate alternatives to ACTs in the treatment of malaria in pregnancy in case resistance emerges. Lapdap ${ }^{\circledR}$ is a synergistic combination of two antifolate drugs (Chlorproguanil and Dapsone) which is rapidly eliminated from the body [8-9] giving it low selection pressure for drug resistance. Most research on Lapdap $\AA$ has been conducted among children with uncomplicated malaria [10]. Our objective was to compare the efficacy (clinical and parasitological response) and safety of Coartem ${ }^{\circledR}$ and Lapdap $\AA$ in the treatment of uncomplicated malaria in pregnancy. Ethical clearance to undertake the study was obtained from the ethical 
committees of the Faculty of Medicine of Makerere University and the Uganda National Council of Science and Technology.

\section{Materials and Methods}

The study was undertaken in Mulago hospital, located in Kampala, Uganda, an urban area with mesoendemic malaria transmission. The study design was an open-label randomized clinical trial. Participants were pregnant women in the second and third trimesters of pregnancy recruited from the antenatal clinic and maternity wards, and followed for the duration of the study. The inclusion criteria were clinical symptoms of fever, joint pains, or general malaise suggestive of uncomplicated malaria, gestation age 14 to 36 weeks, absence of signs or symptoms of complicated malaria, and a thick blood film positive for Plasmodium falciparum monoinfection. Patients with history of allergy to Sulphonamides or who had received antimalarials or Co-trimoxazole therapy in the previous 2 weeks were excluded.

\section{Procedures}

On consent, blood slides were taken and tested for malaria parasites. Participants with parasite density of 500 to 200,000 (parasites per micro liter) were enrolled into the study and randomized using computer-generated numbers to receive (orally) either Coartem ${ }^{\circledR}$ (Artemether $20 \mathrm{mgs}$-Lumefantrine $200 \mathrm{mgs}$ ) or Lapdap $\AA$. The random numbers were generated by a statistician, who sealed them in opaque envelopes. If a potential participant met the inclusion criteria, an envelope was opened and the patient was assigned that treatment. Treatment started on the day of enrollment (Day 0) whereby the participant swallowed the first dose of the drugs in the presence of the study nurse. Subsequent doses (Coartem $\AA$ four tablets twice daily or Lapdap $\AA$ two tablets twice daily) were taken on the following two days.

The study variables included sociodemographic characteristics, obstetric history and medical history, as well as symptoms and signs. Primary endpoints were clinical and parasitological response assessed by parasite densities on blood slides on Days 0, 1, 2, 4, 714 and 28. Adverse effects of the drug (assessed by hematological, renal, and liver function tests on Days 0,14 and
28) as well as clinical assessment were documented and compared.

\section{Sample size}

The sample size of 55 per group was calculated using the formulae by Pocock [11] for randomized clinical trials: $N=(Z \alpha+Z \beta) 2 \square P 1(1-$ $P 1)+P 2(1-P 2) /(P 1-P 2) 2$ where $Z \alpha$ and $Z \beta$ are standard Normal values corresponding to the $95 \%$ confidence interval (1.96) and power of $90 \%$ (1.28) respectively; and $\mathrm{P} 1$ is the proportion of patients with parasite clearance at Day 14 by Coartem $\AA$ (99\%) (3); P2 the corresponding proportion for Lapdap® $(81.5 \%)$ [10].

\section{Data analysis}

The data was analyzed using the Statistical Package for Social Sciences (SPSS Version 10.1). At analysis, baseline characteristics in the two groups were compared, and relative risks (and their $95 \%$ confidence limits) were calculated. The proportion of early and late treatment failures, relapses and adverse effects were compared. The mean fever and parasite clearance times for the two groups were compared using the Student ttest. Analysis was by intention to treat.

\section{Results}

Three hundred seventy-nine patients were screened from January-May 2006. Of these, 128 with positive thick blood smears for uncomplicated Plasmodium falciparum malaria in pregnancy were found eligible for inclusion in the study. The other 251 women were excluded as they had no malaria parasites, had used antimalarial drugs recently, or had infection with multiple species. Of the 128 participants, 114 gave consent to participate in the study. These were enrolled and randomized to treatment with either Lapdap $\AA$ or Coartem $\AA$ (58 per group, for whom only 50 had assessment of the primary and secondary end-points). Three developed severe malaria and were excluded from the study, while two in each arm were lost to follow up.

\section{Baseline characteristics}

The commonest presenting symptoms were headache $(92.7 \%)$ and joint pains $(65.5 \%)$, generalized body weakness (80\%), vomiting or nausea $(50 \%)$ and muscle aches $(38.2 \%)$. Thirtyone $(28.2 \%)$ patients had temperatures greater 
than $37.5^{\circ} \mathrm{C}$ and $26(23.6 \%)$ patients had mild jaundice. Sixty-one participants (55.5\%) had taken some form of treatment prior to enrollment: antipyretics 24 (23.6\%) versus $18(32.7 \%)$ for the Coartem $\AA$ group and the Lapdap $\AA$ group respectively, while all were on hematinics. Table 1 shows the baseline characteristics of the participants, whose difference was not statistically significant. The mean age of the participants was $23.60 \pm 5.20$ for the Coartem $\AA$ group compared to $23.50 \pm 5.30$ for the Lapdap $\AA$ group. The mean gestation age was $28.9 \pm 5.4$ weeks for the Coartem® group compared to $27.3 \pm 6.3$ weeks for the Lapdap® group.

Table 1. Baseline Socio-demographic Characteristics, Clinical Features and Laboratory characteristics of the Study Patients.

\begin{tabular}{|c|c|c|c|}
\hline \multirow[b]{2}{*}{ Education Level } & $\begin{array}{c}\text { Coartem }{ }^{\circledR} \\
(\mathrm{n}=57) \\
(\%)\end{array}$ & $\begin{array}{c}\text { Lapdap }{ }^{\circledR} \\
(n=57) \\
(\%)\end{array}$ & \multirow[t]{2}{*}{ p } \\
\hline & & & \\
\hline No formal education & $2(3.6)$ & $1(1.8)$ & \multirow{5}{*}{0.423} \\
\hline Primary & $27 \quad(45.5)$ & $26 \quad(47.3)$ & \\
\hline Secondary & $27 \quad(49.1)$ & $30(50.9)$ & \\
\hline \multirow{2}{*}{\multicolumn{4}{|c|}{ Parity }} \\
\hline & & & \\
\hline Prime gravida & $18 \quad(32.7)$ & $24(40.0)$ & \\
\hline Secondigravidae & $14(25.5)$ & $10(18.2)$ & \\
\hline 3 and above & $25 \quad(41.8)$ & $23 \quad(41.8)$ & \\
\hline †Age (years) & $23.5 \pm 5.29$ & $23.6 \pm 5.20$ & 0.678 \\
\hline $\begin{array}{l}\text { Median Temperature } \\
\text { at enrolment into } \\
\text { study }\left({ }^{\circ} \mathrm{C}\right)\end{array}$ & 36.9 & 36.6 & 0.780 \\
\hline $\begin{array}{l}\text { †Mean } \\
\text { Parasitaemia/ } \mu \text { l }\end{array}$ & \multirow[t]{2}{*}{$24900.0 \pm 3368.2$} & \multirow[t]{2}{*}{$305716 \pm 4227.2$} & \multirow[t]{2}{*}{0.238} \\
\hline Gestational Age & & & \\
\hline $\begin{array}{l}13-26 \\
27-39\end{array}$ & $\begin{array}{ll}16 & (25.5) \\
41 & (74.5)\end{array}$ & $\begin{array}{ll}23 & (41.8) \\
34 & (58.2)\end{array}$ & 0.098 \\
\hline \multicolumn{4}{|l|}{ Headache } \\
\hline $\begin{array}{l}\text { Yes } \\
\text { No }\end{array}$ & $\begin{aligned} 50 & (90.9) \\
5 & (9.1)\end{aligned}$ & $\begin{aligned} 52 & (94.5) \\
3 & (5.5)\end{aligned}$ & 0.562 \\
\hline \multicolumn{4}{|l|}{ Nausea or Vomiting } \\
\hline Yes & $28 \quad(66.5)$ & $27 \quad(65.5)$ & \multirow[t]{2}{*}{0.365} \\
\hline \multicolumn{3}{|l|}{$\begin{array}{l}\text { No } \\
\text { Joint Pains }\end{array}$} & \\
\hline Yes & $36 \quad(65.5)$ & $36(65.5)$ & \multirow[t]{2}{*}{0.235} \\
\hline $\begin{array}{l}\text { No } \\
\text { Jaundice (Mild) }\end{array}$ & $19(34.5)$ & $19(34.5)$ & \\
\hline Yes & $10 \quad(29.1)$ & $16(18.2)$ & 0.235 \\
\hline No & $45 \quad(70.9)$ & $39(81.8)$ & \\
\hline
\end{tabular}

\section{Follow-up and Treatment Outcomes}

Three participants (two and one in the Lapdap $\AA$ and Coartem $\AA$ arms respectively) developed severe malaria and were given quinine therapy, while ten (five from each treatment arm) were lost to follow-up. For all participants, renal and liver function tests remained within normal range by Day 28 of follow-up. Other than the 3 who developed severe malaria, no severe adverse events were reported by any participant. By Day 2, there were 13 participants (23.6\%) on Lapdap® who had fever (one had hyperpyrexia with a temperature of $40.3^{\circ} \mathrm{C}$ and was given parenteral Quinine). None reported fever by Day 7. For the Coartem® arm, 5 (9.1\%) participants reported fever by Day 2, though by Day 7 none reported fever. Mean fever clearance time was 2.1 days and 2.4 days for Lapdap $\AA$ and Coartem $\AA$ respectively ( $p$-value 0.087). Participants who received Coartem $\AA$ had parasites cleared from their blood faster than those on Lapdap $\AA$, such that by Day 2, all except one had no parasitaemia. Of participants who received Lapdap $\AA$, four had not cleared parasitaemia by Day 2, though by Days 7, 14 and 28, none had parasitaemia. Mean parasite clearance time for Coartem ${ }^{\circledR}$ and Lapdap $\AA$ was 2.2 and 2.4 days respectively (difference not statistically significant) (Table 2).

Table 2. Fever and parasite clearance by Lapdap $\AA \AA$ and Coartem®®十.

\begin{tabular}{|c|c|c|c|c|}
\hline Variable & $\begin{array}{c}\text { Coartem }{ }^{\circledR} \\
\text { n } \quad(\%)\end{array}$ & $\begin{array}{c}\text { Lapdap }{ }^{\circledR} \\
\text { n (\%) }\end{array}$ & $\begin{array}{l}\text { Risk } \\
\text { ratio }\end{array}$ & $95 \% \mathrm{Cl}$ \\
\hline \multicolumn{5}{|l|}{$\begin{array}{l}\text { Fever } \\
\text { Clearance } \\
\text { Dav? }\end{array}$} \\
\hline Yes $(n=87)$ & 47 (85.5) & 40 (72.7) & 1.94 & $0.90-4.20$ \\
\hline No $(n=18)$ & $5 \quad(14.5)$ & 13 (27.3) & & \\
\hline \multicolumn{5}{|l|}{ Day 7} \\
\hline Yes $(n=98)$ & 49 (89.1) & 49 (89.1) & 1.00 & $0.50-1.92$ \\
\hline No $(n=2)$ & $0(0.0)$ & $2(3.6)$ & & \\
\hline \multicolumn{5}{|l|}{ Day 14} \\
\hline Yes $(n=97)$ & 48 (87.3) & 49 (89.1) & 0.92 & $0.53-1.58$ \\
\hline No $(n=0)$ & & & & \\
\hline \multicolumn{5}{|l|}{$\begin{array}{l}\text { Parasite } \\
\text { clearance } \\
\text { Day } 2\end{array}$} \\
\hline Yes $(n=97)$ & 49 (89.1) & 48 (87.3) & 1.18 & $0.49-2.84$ \\
\hline No $(n=7)$ & $3(5.4)$ & $4(7.21)$ & & \\
\hline \multicolumn{5}{|l|}{ Day 7} \\
\hline Yes $(n=98)$ & 40 (72.7) & 48 (87.3) & - & - \\
\hline No $(n=1)$ & $0(0.0)$ & 1 (1.8) & & \\
\hline \multicolumn{5}{|l|}{ Day 14} \\
\hline Yes $(n=97)$ & 48 (87.3) & 49 (89.1) & - & - \\
\hline No $(n=1)$ & $1(1.8)$ & $0(0.0)$ & & \\
\hline \multicolumn{5}{|l|}{ Day 28} \\
\hline Yes $(n=98)$ & $49(100.0)$ & $49(100.0)$ & - & - \\
\hline No $(n=0)$ & $0(0.0)$ & $0(0.0)$ & & \\
\hline
\end{tabular}

$\dagger$ Principle of intention to treat used in analysis.

Of 114 participants enrolled, 10 were lost to follow-up and three developed severe malaria (and were given Quinine therapy). Adverse effects such as anaemia, dark-colored urine or cyanosis were not observed in the Lapdap $\AA$ arm and only 
vomiting (1), diarrhoea (1) and palpitations (1) were reported. In the Coartem $\AA$ arm, the reported adverse effects were palpitations (4), dizziness (1), drowsiness (1) and generalized skin rash (1).

\section{Discussion}

There was no statistically significant difference in clinical and parasitological response of uncomplicated malaria in pregnancy to treatment with Coartem $\AA$ or Lapdap $\AA$ and both drugs were well tolerated. The findings are comparable to studies among pregnant women in which a short fever and parasite clearance times for Lapdap ${ }^{\circledR}$ $[10,12]$ and Artemether-Lumefantrine [13] were demonstrated. The faster parasite clearance time by Coartem $\AA$ could be due to the Artemether component of the drug, which causes rapid initial parasite clearance, with clearance times for fever, parasite ands gametocytes shorter than those of other antimalarials [13].

All participants completed their 3-day course of both drugs, which concurs with an adherence study done in children in Mbarara, Uganda, in which good patient compliance with the 6-dose regimen of Coartem ${ }^{\circledR}$ [14] was reported. Both treatments were well tolerated and no serious adverse events were reported.

Chlorproguanil (a derivative of Proguanil) is considered safe during pregnancy [10,12,15-19]. Dapsone has been extensively used in pregnant women with leprosy, without adverse effects [20]. Many Coartem $\AA$ tablets are required to complete the treatment dose. Failure to complete the course could lead to development of resistance. In contrast, Lapdap $®$ with a shorter half-life has a low propensity to select resistant parasites. As a limitation, participants were followed for only 28 days, so later complications after this period or late pregnancy outcomes such as preterm labour, congenital malformations and low birth weight were not assessed. However, in the literature, no studies have reported any such events as a result of either Coartem $\AA$ or Lapdap $\AA$ or the component drugs. Therefore, while we acknowledge this limitation, we believe Lapdap $\AA$ should be considered a safe and effective alternative to ACT in the treatment of uncomplicated malaria in pregnancy during the second and third trimesters. A larger study with a longer duration of follow-up should be conducted to assess parasite clearance up to Day 42 since Coartem ${ }^{\circledR}$ has a long half-life.
Artemether-Lumefantrine and ChlorproguanilDapsone have high and comparable cure rates and tolerability when used for treatment of uncomplicated malaria in pregnancy.

\section{Acknowledgements}

The authors acknowledge with gratitude financial support for this research from the Ministry of Health, Uganda. They also acknowledge the permission from Mulago hospital, Kampala, Uganda, the permission from the participants, and the contributions of the research assistants.

\section{References}

1. Staedke SG, Mpimbaza A, Kamya MR, Nzarubara BK, Dorsey G, Rosenthal PJ (2004) Combination treatment for uncomplicated malaria in Kampala, Uganda: a randomized clinical trial. Lancet 364: 1950-1957.

2. 2 Nosten F, Van Vugt M, Price R et al (2000) Effects of Artesunate-Mefloquine combination on incidence of Plasmodium falciparum malaria and Mefloquine resistance in western Thailand; a prospective study. Lancet 356: 297-302.

3. Mutabingwa TK, Heller AD, Hallet R, et al (2005) Amodiaquine alone, AmodiaquineSulfadoxine,Sulfadoxine-pyrimethamine,

Amodiaquine/Artesunate, and Artemether-Lumefantrine for outpatient treatment of malaria in Tanzanian children: a four-arm randomized effectiveness trial. Lancet 365 : 1474-80.

4. McGready R et al. (1998) Artemisinin-derivatives in the treatment of Plasmodium falciparum malaria in pregnancy. Transactions of the Royal Society of Tropical Medicine and Hygiene 92: 430-- 433.

5. McGready R et al. (2000) Randomized comparison of Mefloquine-Artesunate versus Quinine in the treatment of multi-drug-resistant falciparum malaria in pregnancy. Transactions of the Royal Society of Tropical Medicine and Hygiene 94: 689-693.

6. McGready R et al. (2000) Randomized comparison of Quinine/Clindamycin versus Artesunate in the treatment of falciparum malaria in pregnancy. Transactions of the Royal Society of Tropical Medicine and Hygiene 95: 651656.

7. Deen JL, Von Sudlein L, Ponder M, Walgraven GE, Greenwood BM (2001) The safety of the combination artesunate and pyrimethamine-sulfadoxine given during pregnancy. Transactions of the Royal Society of Tropical Medicine and Hygiene 95: 424-428.

8. 8 Watkins, WM, Mosobo M (1994) Treatment of plasmodium falciparum with pyrimethamine and sulphadoxine; a selective pressure for resistance in a function of long elimination half-life. Transactions of the Royal Society of Tropical Medicine and Hygiene 87: 7579.

9. Winstanley PW, Watkim D, Muhia I, Szwandt F, Amukoye E, Mansh K (1997) Chloroproguanil-Dapsone for uncomplicated falciparum malaria in young children: Pharmacokinetics and therapeutic range. Transactions of the Royal Society of Tropical Medicine and Hygiene 91: 322-327. 
10. Mutabingwa TK et al. (2001) A trial of ChlorproguanilDapsone in comparison with sulphadoxine/Pyrimethamine for the clearance of plasmodium falciparum infection in Tanzania. Transactions of the Royal Society of Tropical Medicine and Hygiene 95: $433-438$.

11. Pocock SJ (1983) Clinical Trials: A practical Approach. John Wiley and Sons Chichester.

12. Sulo J et al. (2002) Chloproguanil-Dapsone versus Sulfadoxine-Pyrimethamine for sequential episodes of uncomplicated falciparum malaria in Kenya and Malawi; A randomized clinical trial. Lancet 2002; 360: 1136-1143.

13. Hutagatung $R$ et al. (2005) A randomized trial of Artemether-Lumefantrine versus Mefloquine-Artemether for the treatment of multi-drug resistant plasmodium falciparum on the western boarder of Thailand. Malaria Journal 22: 46.

14. Fogg $C$ et al. (2004) Adherence to a 6-dose regimen of Artemether-Lumefantrine for treatment of uncomplicated plasmodium falciparum in Uganda. Am $\mathrm{J}$ Trop Med Hyg 71 (5): 525.

15. Keuter $\mathrm{M}$ et al. (1990) Comparison of Chloroquine, Pyrimethamine-Sulphadoxine, and ChloroproguanilDapsone as treatment for falciparum malaria in pregnant and non-pregnant women in Kakamega District, Kenya. British Medical Journal 301: 466-470.
16. Phillips-Howard PA et al. (1998) Safety of Mefloquine and other antimalarial agents in the first trimester of pregnancy. Journal of Travel Medicine 5: $121-126$.

17. Mutabingwa T et al. (2001) Chloroproguanil-Dapsone for treatment of drug-resistant falciparum malaria in Tanzania. Lancet 358: 1218-1223.

18. Norsten F, Brasseur P (2002) Combination therapy for malaria: the way forward? Drug Safety 62: 1315-1329.

19. Krudsood S, Imwong M, Wilairatana P, Pukrittayakamee S, Nonprasert A, Snounou G, White NJ, Looareesuwan S (2005) Artesunate-dapsone-proguanil treatment of falciparum malaria: genotypic determinants of therapeutic response. Trans R Soc Trop Med Hyg 99(2):142-9.

20. Kahn G (1985) Dapsone is safe during pregnancy. Journal of the American Academy of Dermatology 13, 838-839.

Corresponding Author: Daniel Kabonge Kaye, Department of Obstetrics and Gynecology, Makerere University Medical School, P.O. Box 7072, Kampala, Uganda, E-mail: dankkaye@yahoo.com

Conflict of interest: No conflict of interest is declared. 